\title{
INTERCONTINENTAL CONVERGENCE OF STREAM FISH COMMUNITY TRAITS ALONG GEOMORPHIC AND HYDRAULIC GRADIENTS
}

\author{
Nicolas Lamouroux, ${ }^{1}$ N. LeRoy Poff, ${ }^{2}$ And Paul L. Angermeier ${ }^{3}$ \\ ${ }^{1}$ Cemagref, Division Biologie des Ecosystèmes Aquatiques, 3 bis quai Chauveau, CP 220, F-69336 Lyon Cedex 09, France \\ ${ }^{2}$ Department of Biology, Colorado State University, Fort Collins, Colorado 80523-1878 USA \\ ${ }^{3}$ United States Geological Survey, Virginia Cooperative Fish and Wildlife Research Unit, Virginia Polytechnic Institute and \\ State University, Blacksburg, Virginia 24061-0321 USA
}

\begin{abstract}
Community convergence across biogeographically distinct regions suggests the existence of key, repeated, evolutionary mechanisms relating community characteristics to the environment. However, convergence studies at the community level often involve only qualitative comparisons of the environment and may fail to identify which environmental variables drive community structure. We tested the hypothesis that the biological traits of fish communities on two continents (Europe and North America) are similarly related to environmental conditions. Specifically, from observations of individual fish made at the microhabitat scale (a few square meters) within French streams, we generated habitat preference models linking traits of fish species to local scale hydraulic conditions (Froude number). Using this information, we then predicted how hydraulics and geomorphology at the larger scale of stream reaches (several pool-riffle sequences) should quantitatively influence the trait composition of fish communities. Trait composition for fishes in stream reaches with low Froude number at low flow or high proportion of pools was predicted as nonbenthic, large, fecund, long-lived, nonstreamlined, and weak swimmers. We tested our predictions in contrasting stream reaches in France $(n=11)$ and Virginia, USA $(n=76)$, using analyses of covariance to quantify the relative influence of continent vs. physical habitat variables on fish traits

The reach-scale convergence analysis indicated that trait proportions in the communities differed between continents (up to $55 \%$ of the variance in each trait was explained by "continent"), partly due to distinct evolutionary histories. However, within continents, trait proportions were comparably related to the hydraulic and geomorphic variables (up to 54\% of the variance within continents explained). In particular, a synthetic measure of fish traits in reaches was well explained (50\% of its variance) by the Froude number independently of the continent. The effect of physical variables did not differ across continents for most traits, confirming our predictions qualitatively and quantitatively. Therefore, despite phylogenetic and historical differences between continents, fish communities of France and Virginia exhibit convergence in biological traits related to hydraulics and geomorphology. This convergence reflects morphological and behavioral adaptations to physical stress in streams.

This study supports the existence of a habitat template for ecological strategies. Some key quantitative variables that define this habitat template can be identified by characterizing how individual organisms use their physical environment, and by using dimensionless physical variables that reveal common energetic properties in different systems. Overall, quantitative tests of community convergence are efficient tools to demonstrate that some community traits are predictable from environmental features.
\end{abstract}

Key words: ANCOVA; community convergence; geomorphology; habitat template; hydraulics; instream habitat models; pool; riffle; stream-fish community.

\section{INTRODUCTION}

Convergence in biogeographically unrelated ecosystems has been observed for many aquatic and terrestrial communities, at different spatial and temporal scales, and using various community properties (e.g., species richness, proportional composition by guild or biological trait; Moyle and Herbold 1987, Wiens 1991, Bastow et al. 1994, Samuels and Drake 1997). Community

Manuscript received 18 December 2000; revised 22 October 2001; accepted 26 October 2001. convergence is an aspect of the hypothesis that characteristics of communities are predictable from their environment (Schluter 1986) and that communities are structured rather than random entities. Models predicting convergence in community traits from independent systems having similar environmental features suggest the existence of key repeated mechanisms underlying community organization. Therefore, while predictive tools in ecology are often site specific and poorly transferable across ecosystems (Peters 1991), convergence studies can provide general models for 
predicting fundamental community patterns in multiple sites.

Convergence analyses at the community level are not always convincing and face several limits (Schluter 1986, Myers and Giller 1988, Samuels and Drake 1997). First, community convergence is generally assessed by either monitoring the evolution of different systems (e.g., Inouye and Tilman 1995) or comparing the effect of similar environmental features on community structure across various sites (e.g., Schluter 1986). Both approaches require large data sets and/or long-term studies. In particular, intercontinental comparisons are difficult because long-term or multisite surveys have generally not been designed consistently on several continents. Second, the comparison of environmental features in two unrelated systems is often assessed qualitatively (e.g., both systems are warm deserts) rather than quantitatively (Schluter 1986, Wiens 1991). Third, given the many processes affecting communities, the environmental variables responsible for community convergence in unrelated systems are generally not identified (Samuels and Drake 1997).

Stream fish are well suited for testing the hypothesis that traits of communities in distant systems converge in response to the environment. First, many lotic fish populations occur in more or less isolated watersheds where they can adapt to their environment. Second, lotic systems are often regulated by similar physical processes and patterns. Variables such as water velocity, water depth, shear stress, or local geomorphology influence the behavior of individual fish (Bovee 1982, Lamouroux et al. 1999a) and/or the characteristics of communities (Gorman and Karr 1978, Statzner et al. 1988, Angermeier and Winston 1998). As a result, physical properties of streams are potential key predictors of fish community patterns (Lamouroux et al. $1999 b$ ). Third, because some biological traits of many fish species are documented, the functional comparison of communities having different species compositions is possible (Bastow et al. 1994, Persat et al. 1994, Poff and Allan 1995).

Several common patterns in fish community organization have been identified among distant river basins at different spatial scales. For example, species richness of whole basins on different continents has been linked to the area, total discharge, and primary productivity of the basins (Oberdorff et al. 1995). Among stream reaches within watersheds, fish communities of various continents show consistent patterns along longitudinal gradients (Verneaux 1981, Schlosser 1982). Within reaches, the influence of microhabitat diversity on species richness has been reported in several basins (Gorman and Karr 1978, Angermeier and Winston 1998). Nevertheless, a general understanding of the degree of convergence of fish communities across zoogeographically distinct basins is lacking, primarily because quantitative comparisons are challenging and because habitat descriptors are often intercorrelated across streams, making it difficult to identify which are responsible for community structure (Horwitz 1978, Schlosser 1982). As a result, few predictive models of patterns of fish communities in unrelated systems are actually available (but see Magnuson et al. 1998).

Habitat template theories, which relate species' traits to habitat characteristics (Southwood 1977, Poff and Ward 1990, Townsend and Hildrew 1994), are general models of species-environment relationships that are not biogeographically restricted. These theories suggest that the spatial and temporal features of the habitat are the major determinants of species traits observed, and could be responsible for community convergence. For example, freshwater species that are small and fecund are expected to dominate in temporally variable environments with low spatial heterogeneity. Nevertheless, observed correlations between the physical habitat (e.g., water depth and flow variability) and aquatic species traits in regional contexts (e.g., Persat et al. 1994, Resh et al. 1994, Poff and Allan 1995, Mérigoux 1998) were generally not as specific or explicit as what is actually predicted by habitat template theories. Several explanations of this poor explanatory power have been proposed. Among them, the effects of a habitat template on freshwater communities may be constrained by hierarchical environmental filters prevailing at the valley, the basin, or larger spatial scales (Tonn et al. 1990, Poff 1997). Phylogeny and the evolutionary history of communities also affect species trait distribution (Mahon 1984, Moyle and Herbold 1987). In addition, species may adapt to their environment by various alternative strategies (Resh et al. 1994). Finally, the spatial and temporal variability of the environment may be perceived differently depending on the variables (and their scaling) used to describe it. In any case, using habitat template theories as general predictive tools of community characteristics initially requires precise definition of the major axes of the habitat template.

An attractive means for quantifying the main axes of the habitat template of communities is to test the predictive power of models based on observations of individual behavior. This is the basic principle of instream habitat models, which predict the consequences for communities at the reach scale (length of stream including several pool-riffle sequences) based on individual fish preferences for hydraulic variables (depth, velocity) observed at the microhabitat scale (i.e., less than a few square meters). These models are used worldwide to quantify the impacts of geomorphologic and hydrological modifications of stream reaches on fish populations (e.g., Bovee 1982, Lamouroux et al. $1999 b$ ). They follow the idea that stream hydraulics is a dominant forcing function in stream ecosystems to which other processes and patterns are linked (Hart and Finelli 1999). However, they have never been used for comparative studies of unrelated communities, perhaps because they focus on species-specific information, 
which limits generality. For example, microhabitat preferences are mostly documented for only a few game species; preferences may change across streams (Leftwich et al. 1997); and species composition changes with zoogeography. Recently, however, Lamouroux et al. $(1999 b)$ utilized these models to predict variation in fish community traits across several zoogeographically similar sites in France. Those results suggest that the trait composition of zoogeographically distinct communities might be predictable.

In this paper, we test the hypothesis that fish community traits on two continents (Europe and North America) converge along hydraulic and geomorphic gradients at the reach scale. Further, we test whether this reach-scale convergence can be predicted solely from observations of microhabitat preferences of individual fish collected within French reaches. Our study still faces some limits of convergence analyses across continents: it is based on heterogeneous large data sets and uses coarse noncomprehensive descriptions of community patterns. However, our main goal is to demonstrate that reach-scale convergence of whole communities can be assessed using key quantitative environmental variables, and can be predicted from observations of microhabitat preferences. To this end, we analyzed fish habitat preference at the local scale (i.e., how traits of fish species were related to microhabitat hydraulics within French reach surveys), and upscaled them to generate a priori predictions relating biological traits of fish communities to hydraulics of stream reaches. We then test our predictions using a large database of fish and habitat samples collected from 87 stream reaches in France and Virginia, USA. Following Schluter's (1986) general approach, reach-scale convergence was analyzed by testing the effects of continent (zoogeography) and physical habitat (geomorphology or hydraulics) on fish community traits, where a comparable effect of physical habitat within both continents indicates convergence. Finally, we discuss the implications of our results for the development of predictive models in community ecology.

\section{Methods \\ Methodological framework}

We used large sets of physical and biological data collected at the local scale (microhabitats of several square meters [Lamouroux et al. 1999b], sampled within eight French stream reaches) and at the reach scale (stream segments including several pool-riffle sequences [Newbury and Gaboury 1993], 11 sampled in France and 76 in Virginia). Because of the multiple data sources involved, we present our methodology in four steps. We describe the materials and methods used in each step, referring to published accounts for additional details.

\section{Step 1. Variables used to describe fish traits, hydraulics and geomorphology}

Biological traits of the species of both continents were collected from the literature and coded similarly (see the Appendix). Species studied were those dominating our communities (see step 3), for which trait information was available. Selected traits describe the body morphology (adult body length, BL; shape factor, $\mathrm{SH}$; swimming factor, $\mathrm{SW}$ ), reproductive potential (fecundity, FE), behavior (position in the water column, VP) and longevity of species (maximum age, MA). Expression of all these traits can be influenced by habitat features (Townsend and Hildrew 1994). Existing knowledge on species traits is sometimes imprecise (e.g., fecundity), and some traits vary across streams and life history stages. In addition, trait category definitions in the literature are inconsistent among authors. For all these reasons, our intercontinental analysis required us to define "coarse" categories for species traits and to associate all individuals of a species with one category for each trait. This was not problematic for our objectives: if a coarse trait description is sufficient to reveal a comparable functional response to the environment across continents, a more precise description of traits would provide stronger results. Potential redundancy among traits was analyzed by calculating the correlation between traits across species (Spearman Rho, a correlation coefficient computed on ranks).

Traits for which there was not a wide range of expression across continents were excluded. For example, Virginia fishes can be classified into many feeding modes (Angermeier 1995), whereas most European species are generalist feeders, which cannot be assigned to fine categories (Persat et al. 1994, Michel and Oberdorff 1995). Traits describing habitat use were also excluded, because they do not reflect directly functional attributes of communities, and they are necessarily related to habitat characteristics used as predictor variables in our analysis.

All fish assemblages (at both microhabitat and reach scales) were described by the proportions of fish individuals associated with each trait category. These proportions were noted $\% \mathrm{BL} 1, \% \mathrm{BL} 2$, and $\% \mathrm{BL} 3$ for the three categories of body length (BL; see the Appendix), and similarly for other traits. Throughout the paper, we use \% TRAIT to indicate any of these proportions.

At both local and reach scales, we described hydraulics using the Froude number, FR. This variable is an important descriptor of stream hydraulics (Yalin 1992), and has been identified as a major predictor of fish community patterns in different stream reaches (Lamouroux et al. 1999b). FR, a dimensionless hydraulic descriptor of the flow habitat, combines water velocity $V$ and water depth $H\left(\mathrm{FR}=V /[g \times H]^{0.5}\right.$, where $g$ is the acceleration due to gravity). To describe hy- 
draulics at a similar discharge rate for each reach, FR was estimated at the reach scale by $\mathrm{FR}=Q_{\mathrm{m}} /$ [ $g^{0.5} H_{\mathrm{m}}^{1.5} W_{\mathrm{m}}$ ], where $Q_{\mathrm{m}}$ is the lowest mean monthly flow in a year (averaged for years over the period of record), and $W_{\mathrm{m}}$ and $H_{\mathrm{m}}$ are the mean width and mean depth, respectively, at $Q_{\mathrm{m}}$. FR of reaches is a hydraulic descriptor linked to geomorphology because FR is low in pool-type habitats and high in riffle-type habitats (Jowett 1993, Lamouroux et al. 1999b). We chose to calculate it for low flow conditions (minimum monthly flow), which can be considered as "bottleneck" conditions for the structure of stream fish communities (cf. Wiens 1977, Lamouroux et al. 1999b).

Geomorphology was described only at the reach scale, but similarly in France and Virginia. In each reach, we estimated the length associated with two different types of morphological units (pool, riffle). All portions of the reach not visually classified as pools or riffles were classified as runs. We defined the variable $\%$ POOL to indicate the proportion of pools vs. riffles (independent of the proportion of runs, because run habitats can have a wide range of hydraulic characteristics; Jowett 1993). Therefore, we defined \%POOL as (proportion of pools +0.5 [proportion of runs]), which is equal to $(1+$ proportion of pools - proportion of riffles)/2. At the reach scale, our hydraulic (FR) and geomorphic (\%POOL) variables were expected to be negatively correlated, because FR is low in pool-type habitats (Jowett 1993, Lamouroux et al. 1999b). However, we used both variables in this study because FR, though potentially more objectively measured, was known in only 9 of 76 Virginia reaches. By contrast, $\%$ POOL was estimated in all reaches, and could be a surrogate for FR when hydraulic data were not available. The links between FR and \%POOL will be analyzed in step 3.

\section{Step 2. Developing local-scale preference models (in France) to predict reach-scale convergence}

In this step, we analyzed how traits of fish species in French streams were related to local-scale hydraulics (FR) within French reach surveys, by generating habitat preference models for each trait. These models were then upscaled to predict reach-scale convergence. Habitat preference models were developed using a total of 1601 microhabitat samples collected during 35 field surveys, conducted in eight reaches of six different streams in southern France (see Lamouroux et al. 1999a for methodological details). An essential point was to construct habitat preference models within surveys, and averaged across surveys, because differences in fish traits among the microhabitats within surveys can confidently be interpreted as preferences relative to hydraulics (temperature and water quality conditions were homogeneous in a given reach on a given date).

The eight reaches were situated in the Rhône, Loire, and Garonne River basins; they had a quasinatural morphology and varying degrees of discharge regulation.
During each survey, fish were collected by electrofishing in independent habitat units, using an open-sampling technique. These microhabitats had surface areas between 6 and $90 \mathrm{~m}^{2}$ (95\% of units), the sampled area increasing with stream width. Microhabitats were chosen within pools, runs, and riffles, at the channel center or its margins (see Vadas and Orth 1993, Thévenet and Statzner 1999, for comparable sampling strategies). Thévenet and Statzner (1999) demonstrated that a comparable sampling procedure captured about $70 \%$ of the fish in habitat units, without significant difference among species and macrohabitats, and with a negligible fright bias. Within each microhabitat, fish were identified to species and measured. Next, three to ten measures of water column velocity and water depth were made at random in the microhabitat. to calculate a mean value for FR for that microhabitat.

A total of 1601 microhabitats (a total of $\sim 40000$ fish) were sampled during the 35 surveys (Lamouroux et al. 1999a). Between 22 and 70 microhabitats were sampled per field survey, and 1-12 independent surveys (separated by several months) were carried out in each reach. Samples were taken during the day, at flows generally below the annual mean, and surveys at each site were distributed similarly among seasons. Of the 1601 microhabitats, 1391 contained fish, 1113 of them had FR values below 0.2. We generated preference models using only these 1113 microhabitats to (1) focus on the range of habitat conditions found in stream reaches where predictions will be tested (FR of reaches described in step 3 were $<0.2$ ), (2) avoid including infrequent high FR values in our analyses (very few habitat units had FR $>0.2$ in some surveys), and (3) avoid working on non-normal FR distributions within surveys.

We used analysis of covariance (ANCOVA) to examine how FR influenced each of the six trait variables across microhabitats within reach surveys. For each trait variable (\%TRAIT), our ANCOVA model was

$$
\% \text { TRAIT }=C_{1} \text { (survey) }+S_{1} \times \text { FR. } \quad(\text { model } 1)
$$

In this model, $C_{1}$ is a constant (intercept) that depends on reach surveys $(n=35)$. It can account for differences in \% TRAIT among reach surveys that might be due to factors other than FR (e.g., temperature, water quality, or migration). $S_{1}$ is a slope parameter that reflects how FR influences \%TRAIT within surveys in southern France (i.e., microhabitat preferences). $S_{1}$ is assumed common to all surveys here, and thus reflects the mean effect of FR on habitat choice within all surveys. We did not investigate $S_{1}$ variation among surveys (e.g., microhabitat preference flexibility due to season or habitat availability; see Lamouroux et al. 1999a) because fish data could be insufficient in some surveys, and our goal was to derive predictions from the mean relations between fish traits and hydraulics at the local scale (as observed over the whole data set). Because we used the local-scale preference analysis to generate 
predictions for the reach-scale convergence analysis, we considered rejection of the null hypothesis $\left(S_{1}=\right.$ $0)$ at $\alpha=0.05$ to indicate a potential influence of hydraulics on fish traits. We estimated the overall strength of trait-habitat relationships at the local scale by examining a posteriori the proportion of trait variables significantly related to FR.

According to model 1, variation in FR at the local scale results in variation in \% TRAIT equal to $S_{1} \times$ (variation in FR). We upscaled this model by assuming that this relationship would remain valid at the reach scale (a reach being a sum of microhabitats). We therefore predicted that \% TRAIT in reaches should be proportional to FR of reaches, and $S_{1}$ should be the slope of this relationship.

To obtain a synthetic multivariate descriptor of assemblage-level trait response to hydraulics, we derived $\%$ SUM, the sum of trait categories most significantly negatively correlated with FR (as shown in Table 2 below). We chose the negatively correlated categories because they were well discriminated from others in the analysis; note that summing the positively correlated categories would be redundant, as category proportions of each trait sum to 1 . We expected \%SUM to be correlated, at the reach scale, with our habitat variables.

\section{Step 3. Reach scale characterizations in France and Virginia}

The effect of hydraulic (FR) and geomorphic (\% POOL) variables on community traits was analyzed using data from 11 reaches in France and 76 in Virginia; each reach included multiple pool-riffle sequences. French reaches were in the Rhône River basin (Lamouroux et al. 1999b), in the Upper Rhône River (upstream from Lyon), the lower Rhône River (downstream from Lyon), the Ain River, and the Ardèche River (mean $\pm 1 \mathrm{SD}$ of width, $83 \pm 30 \mathrm{~m}$; depth, 1.1 $\pm 0.6 \mathrm{~m}$; velocity, $0.27 \pm 0.15 \mathrm{~m} / \mathrm{s}$ ). They had littlemodified morphology, but discharges were affected by a wide range of regulation types. Three of the 11 reaches were used to generate our predictions (they belonged to the eight reaches used in step 2). However, all 11 reaches were used to test our predictions because (1) the preference models generated in step 2 focused on within-stream differences in fish density among microhabitats, whereas our focus herein is betweenstream differences in community patterns, and (2) tests of our predictions excluding these three reaches gave comparable quantitative results.

Reaches in Virginia were not used to generate predictions. They were selected from a large database of $>300$ sites sampled during a statewide stream survey (see Angermeier and Winston 1998). Site selection was based on sampling adequacy and lack of severe human impacts. Though not pristine, their morphology and physicochemical quality was little impacted (Angermeier and Winston 1998). Reaches in Virginia differed from French reaches. They were smaller (mean $\pm 1 \mathrm{SD}$ of width, $13 \pm 3 \mathrm{~m}$; depth, $0.4 \pm 0.2 \mathrm{~m}$; velocity, 0.16 $\pm 0.06 \mathrm{~m} / \mathrm{s})$ and distributed among four major drainage basins (Chesapeake Bay, Atlantic Ocean, Ohio River, and Tennessee River) with few intrastream replicates.

In France, fish were collected by a variety of electrofishing techniques and sampling teams during field surveys made at different seasons over periods of $2-$ 13 yr (1982-1994), depending on the reach (see Lamouroux et al. 1999b). In all cases, open-sampling techniques were used, as they are suited to describe relative abundances of species in large streams (Persat and Copp 1990, Vadas and Orth 1993, Thévenet and Statzner 1999). As described in step 2, habitat units several square meters in area were sampled within each reach during several surveys, using a stratified-random sampling strategy (the number of habitat units in pools, riffles or runs was proportional to the area of these morphological units). Community characteristics (trait proportions) were estimated for each survey, then averaged across surveys to provide time-averaged estimates of community traits (see Poff and Allan 1995 for a similar approach). The 14 species considered herein (for which trait information was available; see the Appendix) accounted for 82-99\% (mean 94\%) of the total abundance in each reach.

In Virginia, one electrofishing collection was made in each reach between 1987 and 1990 (see Angermeier and Winston 1998). Fish were collected from consecutive sequences of individual morphological units (e.g., pools or riffles), which were blocked with nets during sampling and electrofished twice in the upstream direction. Data from individual units were pooled to calculate community trait proportions in each reach. Therefore, fish samples in Virginia were more intensive (in space) but less repeated (in time) than in France. A total of 106 species from Virginia was included in our study (see the Appendix), and they represented $87 \%$ to $100 \%$ (mean $99 \%$ ) of the total abundance in each reach. The total data set (France and Virginia) included $\sim 100000$ fish.

To characterize hydraulic conditions (FR at low flow) in French reaches, the mean depth $H_{\mathrm{m}}$ and width $W_{\mathrm{m}}$ of each reach at $Q_{\mathrm{m}}$ were estimated using hydraulic geometry relationships (width-discharge and depthdischarge relationships) fitted to standard power functions $\left(W=a Q^{b}, H=c Q^{f}\right.$, where $W, H$, and $Q$ are width, depth, and discharge, respectively; see Knighton 1998:171). In each reach, these relationships were calibrated using depth and width measurements made along cross-sections at different discharges, or using numerical hydraulic models (Lamouroux et al. 1999b). Discharge histories during $10 \mathrm{yr}$ including the fish sampling period were derived from fixed gauging stations or relevant power plant operation schedules, and were used to estimate $Q_{\mathrm{m}}$, except in one reach where only 3 yr were available. FR values in France were estimated 
from numerous measurements at various discharges, and represent precise estimates of reach hydraulics.

In Virginia, extensive hydraulic and discharge measurements were available for only 9 of the 76 reaches. As for French reaches, the mean depth $H_{\mathrm{m}}$ and width $W_{\mathrm{m}}$ of each reach corresponding to the monthly minimum flow $Q_{\mathrm{m}}$ were estimated using hydraulic geometry (depth-discharge and width-discharge) relationships fitted to power functions ( $W=a Q^{b}, H=c Q^{f}$ ). However, the depth and width measurements needed to calibrate these relationships were available for only one discharge (see Angermeier and Winston 1998) differing from $Q_{\mathrm{m}}$. In each of the nine reaches, a mean central depth was determined from measurements taken along the thalweg. Comparisons of the whole-channel mean water depth and the mean central depth in 10 reaches of Virginia (other than those studied but for which both statistics were available) indicated that the two variables were strongly associated $\left(r^{2}=0.94, P<0.01\right)$. This enabled us to estimate the mean depth in all Virginia reaches. To fit the width-discharge and depthdischarge relationships to power functions, estimates of width and depth at a single discharge are insufficient. We solved this problem by fixing the exponent values of the power functions ( $b$ and $f$, which are generally homogeneous within a region and vary little across regions) equal to the mean value provided in the literature ( $b=0.2, f=0.4$; Dunne and Leopold 1978, Gordon et al. 1992, Knighton 1998). Discharge histories (during $18 \mathrm{yr}$ including the sampling period) were given for each reach by a fixed gauging station of the U.S. Geological Survey, and were used to estimate $Q_{\mathrm{m}}$. Gauges were relatively close to the reaches $(<15 \mathrm{~km})$, thereby minimizing potential bias to $Q_{\mathrm{m}}$ caused by tributaries between the studied reaches and the gauges. Hydraulic data in Virginia reaches were less precise than in French reaches, but were reliable estimates of physical characteristics in Virginia due to the broad generality of hydraulic geometry relationships (Gordon et al. 1992).

The geomorphology of reaches (\%POOL) was documented similarly in all 11 French and 76 Virginia reaches, by measuring the length associated with geomorphological units (pools and riffles, visually assessed). In reaches where data were available for both FR and \%POOL (11 in France and 9 in Virginia), the relationship between our two physical variables was analyzed by linear regression. This enabled us to estimate the effect of \%POOL on community traits, from predictions made using FR as the habitat variable (described by $S_{1}$ in model 1 , see step 2 ).

\section{Step 4. Testing for reach-scale community convergence across continents}

In this step, we adapted the ANOVA approach of community convergence developed by Schluter (1986), which allowed us to test simultaneously the effects of continent (zoogeography) and physical habitat (geo-

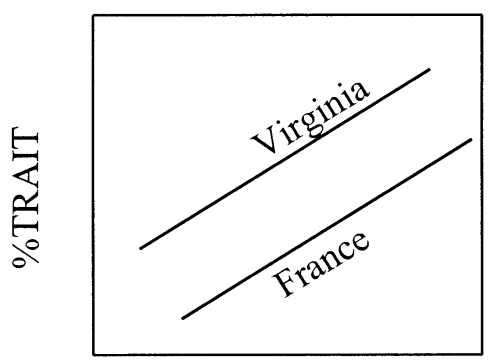

\section{FR or $\%$ POOL}

FIG. 1. Convergence at the reach scale was analyzed by comparing, between continents, the effect of each habitat variable on each trait variable within continents. Convergence was indicated by (1) the lack of a significant interaction between the effect of the habitat variable and the continent (i.e., the two slopes in the figure do not differ) and (2) a significant effect of the habitat variable on the trait variable (a mean slope, fitted for reaches of both continents, is significantly different from 0 ).

morphology or hydraulics) on trait proportions in the community. Following Schluter (1986), a comparable effect of geomorphology/hydraulics on community traits within continents indicates convergence (Fig. 1). We tested if the observed intercontinental convergence corresponded (qualitatively and quantitatively) to the predictions derived from studies of fish assemblages made at the local scale in France (step 2).

We analyzed community convergence using variables defined at the reach scale. To avoid redundancy, the effects of FR and \%POOL on \% TRAIT were tested for the category of each of the six trait variables found to be most negatively correlated with FR in step 2 (proportions of each trait categories sum to 1; if one category is negatively correlated with FR, the sum of the others shows an inverse relation). We also tested the effects of the habitat variables on \%SUM, the multivariate summation of the six trait categories. Convergence was analyzed using the ANCOVA models

$$
\begin{array}{ll}
\left.\% \text { TRAIT }=C_{2} \text { (continent }\right)+S_{2} \times \text { FR } & (\text { model } 2) \\
\left.\% \text { TRAIT }=C_{3} \text { (continent }\right)+S_{3} \times \% \text { POOL } & (\text { model } 3)
\end{array}
$$

Model 2 was tested using only the subset of Virginia reaches with hydraulic data, whereas model 3 was tested using all reaches. Models 2 and 3 are derived from Schluter's (1986) ANOVA approach of community convergence, but are adapted to deal with quantitative habitat variables. In these models, $C_{2}$ and $C_{3}$ are constants (intercepts) that depend on the continent. They account for continental differences in \% TRAIT that are not necessarily due to differences in FR or \% POOL. $S_{2}$ and $S_{3}$ are intercontinental slopes (shared by both continents) that reflect how FR and \% POOL, respectively, are related to community trait proportions among reaches, within continents. We considered rejection of the null hypothesis $S_{2}=0$ (respectively, $S_{3}$ 
TABlE 1. Correlation matrix for species traits (Spearman rho, calculated over the 120 species of the Appendix).

\begin{tabular}{lrrrrr}
\hline \hline & \multicolumn{5}{c}{ Correlation with other traits } \\
\cline { 2 - 6 } Traits & \multicolumn{1}{c}{ BL } & \multicolumn{1}{c}{ FE } & MA & VP & SH \\
\hline FE & $\mathbf{0 . 6 3}$ & & & & \\
MA & $\mathbf{0 . 7 0}$ & $\mathbf{0 . 6 0}$ & & & \\
VP & 0.12 & 0.15 & -0.04 & & \\
SH & -0.04 & -0.02 & -0.09 & $-\mathbf{0 . 4 0}$ & \\
SW & $-\mathbf{0 . 2 2}$ & -0.14 & -0.05 & $-\mathbf{0 . 3 0}$ & -0.00 \\
\hline
\end{tabular}

Notes: Significant associations $(P<0.05)$ are boldface. Codes of traits correspond to body length (BL), fecundity (FE), maximum age (MA), vertical position (VP), shape factor $(\mathrm{SH})$ and swimming factor $(\mathrm{SW})$; see the Appendix for trait definitions.

$=0$ ) at $\alpha=0.10$ (corrected for multiple tests using the sequential Bonferroni correction; Sokal and Rohlf 1998:241) to indicate a significant effect of FR (respectively, \%POOL) on \% TRAIT. The starting value of $\alpha=0.10$ was chosen because we performed onetailed tests (we predicted the sign of the effect of the habitat value in step 2). We tested if $S_{2}$ (and $S_{3}$ ) differed among continents (i.e., whether $S_{2}$ interacted with continent in model 2). If $S_{2}$ did not interact with continent and was significantly different from 0 , then we inferred community convergence (Fig. 1).

We repeated similar covariance tests to investigate if the effect of \%POOL on \%TRAIT differed across the five major basins from which samples were taken (Rhône basin in France; Chesapeake Bay, Atlantic Ocean, Ohio River, and Tennessee River basins in Virginia). For this purpose, we used basin instead of continent as the categorical variable in model 3. To avoid redundancy and the multiplicity of analyses, these tests were performed only for the synthetic trait variable, $\%$ SUM.

Finally, to test if intercontinental convergence was predicted from observations made in France at the local scale, we compared the influence of FR on \% TRAIT at the reach scale (described by $S_{2}$ in model 2) to that predicted from local-scale studies (described by $S_{1}$ in model 1, see step 2). In cases where reach-scale convergence was observed, a similar sign for $S_{1}$ and $S_{2}$ indicated that community convergence was qualitatively predicted. If, in addition, $S_{1}$ fell in the $95 \%$ confidence interval for $S_{2}$, community convergence was quantitatively predicted. Using the linear relationship between FR and \%POOL across reaches developed in step 3, we also compared the influence of \%POOL on $\%$ TRAIT at the reach scale (described by $S_{3}$ in model 3 ) to that predicted from local scale studies $\left(S_{1}\right.$ in model 1).

\section{RESULTS}

Fish communities from France and Virginia had only one species in common (Appendix), and species richness was much higher in Virginia. Virginia species were of numerous families, whereas French fishes were mostly cyprinids. Our species traits were only slightly redundant. The 15 correlation coefficients between traits calculated over the 120 species were all $\leq 0.7$; 9 coefficients were $\leq 0.15$ (Table 1 ).

\section{Developing local-scale preference models (in \\ France) to predict reach-scale convergence}

Local values of FR influenced significantly the traits of fish assemblages within reach surveys ( 15 out of 18 $P$ values are $<0.05$ in Table 2$)$. In particular, \%BL3, $\% \mathrm{FE} 3, \% \mathrm{MA} 4, \% \mathrm{VP} 2, \% \mathrm{SH} 1$, and \%SW3 were the categories of each trait found to be the most negatively correlated with FR. Therefore, within fish surveys in France, microhabitats with low FR (corresponding to pool-type habitats) tend to contain proportionally more fish that are nonbenthic, large, fecund, long-lived, nonstreamlined, and weak swimmers.

Despite the strong statistical influence of FR on fish traits, the variance in fish traits explained by FR at the local scale, within surveys, remained low $(<5.8 \%$; Table 2), indicating high scatters around trends observed at this scale. The sum of the six trait proportions listed above (\%SUM) was better explained $(6.0 \%$ of its variance within reaches explained by FR).

TABLE 2. Results of covariance models developed to analyze fish microhabitat preferences within French reaches (model 1 in Methods, fitted using 1113 microhabitat samples).

\begin{tabular}{|c|c|c|c|c|c|}
\hline$\%$ TRAIT & $\begin{array}{c}\text { Survey } \\
\text { effect } P \\
(n=35)\end{array}$ & $\begin{array}{c}\text { FR } \\
\text { effect } P\end{array}$ & $\mathrm{~S}_{1}$ & $\begin{array}{c}\text { Vari- } \\
\text { ance } \\
\text { survey }\end{array}$ & $\begin{array}{c}\text { Vari- } \\
\text { ance } \\
\text { FR }\end{array}$ \\
\hline$\%$ BL1 & $<0.001$ & 0.041 & 0.19 & 46 & 0.4 \\
\hline$\%$ BL2 & $<0.001$ & 0.007 & 0.50 & 18 & 0.7 \\
\hline$\% \mathbf{B L} \mathbf{3}$ & $<\mathbf{0 . 0 0 1}$ & $<\mathbf{0 . 0 0 1}$ & -0.69 & 10 & 1.2 \\
\hline$\%$ FE1 & $<0.001$ & 0.041 & 0.19 & 46 & 0.4 \\
\hline$\%$ FE2 & $<0.001$ & $<0.001$ & 0.51 & 27 & 1.2 \\
\hline$\%$ FE3 & $<\mathbf{0 . 0 0 1}$ & $<\mathbf{0 . 0 0 1}$ & -0.71 & 15 & 3.5 \\
\hline$\%$ MA2 & $<0.001$ & 0.041 & 0.19 & 46 & 0.4 \\
\hline$\%$ MA3 & $<0.001$ & $<0.001$ & 0.89 & 17 & 2.1 \\
\hline \% МА4 & $<\mathbf{0 . 0 0 1}$ & $<\mathbf{0 . 0 0 1}$ & -1.09 & 14 & 2.9 \\
\hline$\% \mathrm{VP} 1$ & $<0.001$ & $<0.001$ & 1.46 & 23 & 5.8 \\
\hline$\% \mathbf{V P 2}$ & $<\mathbf{0 . 0 0 1}$ & $<\mathbf{0 . 0 0 1}$ & -1.46 & 23 & 5.8 \\
\hline$\%$ SH1 & $<0.001$ & $<\mathbf{0 . 0 0 1}$ & -0.39 & 24 & 2.8 \\
\hline$\% \mathrm{SH} 2$ & $<0.001$ & 0.019 & -0.31 & 9 & 0.6 \\
\hline$\% \mathrm{SH} 3$ & $<0.001$ & 0.051 & 0.32 & 24 & 0.3 \\
\hline$\%$ SH4 & $<0.001$ & 0.002 & 0.38 & 20 & 0.9 \\
\hline$\% \mathrm{SW} 1$ & $<0.001$ & 0.946 & 0.01 & 26 & 0.0 \\
\hline$\% \mathrm{SW} 2$ & $<0.001$ & 0.103 & 0.21 & 30 & 0.3 \\
\hline$\% \mathbf{S W 3}$ & $<\mathbf{0 . 0 0 1}$ & $<\mathbf{0 . 0 0 1}$ & -0.21 & 9 & 1.2 \\
\hline$\%$ SUM & $<0.001$ & $<\mathbf{0 . 0 0 1}$ & -4.55 & 15 & 6.0 \\
\hline
\end{tabular}

Notes: Models predict the proportions of individuals with particular categories of biological traits in a microhabitat (\% TRAIT, see Methods for codes) from hydraulics (FR, the Froude number, used as covariate) and reach survey (used as categorical variable). "Survey effect"' indicates whether the effect of reach survey is significant (cases where $P<0.05$ ). "FR effect" indicates whether the effect of FR is significant (i.e., the slope $S_{1}$ associated with the effect of FR differed from 0 ; cases where $P<0.05)$. "Variance survey" is the percentage of variance explained by the reach survey alone. "Variance FR" is the percentage of within-survey variance explained by FR. For each trait, the boldface category is most negatively associated with FR and will be used in subsequent tables. 
TABLE 3. Results of covariance models (model 2 in Methods) tested in reaches of France ( $n$ $=11)$ and Virginia $(n=9)$.

\begin{tabular}{|c|c|c|c|c|c|c|}
\hline$\%$ TRAIT & $\begin{array}{l}\text { Continent } \\
\text { effect } P\end{array}$ & $\begin{array}{c}\text { FR } \\
\text { effect } P\end{array}$ & $\begin{array}{c}\text { FR } \times \\
\text { continent }\end{array}$ & $S_{2}$ & $\begin{array}{c}\text { Variance } \\
\text { conti- } \\
\text { nent }\end{array}$ & $\begin{array}{c}\text { Variance } \\
\text { FR }\end{array}$ \\
\hline$\% \mathbf{B L 3}$ & $<0.01(-)$ & 0.017 & 0.80 & $-1.48( \pm 1.20)$ & 38 & 29 \\
\hline$\% \mathbf{F E 3}$ & $0.05(-)$ & 0.002 & 0.67 & $-1.45( \pm 0.86)$ & 15 & 42 \\
\hline \%МA4 & $<0.01(-)$ & $<\mathbf{0 . 0 0 1}$ & 0.97 & $-1.91( \pm 0.90)$ & 47 & 54 \\
\hline$\% \mathrm{VP} 2$ & $0.22(-)$ & 0.860 & 0.10 & $-0.08( \pm 0.98)$ & 9 & 1 \\
\hline$\%$ SH1 & $<0.01(+)$ & 0.240 & 0.91 & $-0.60( \pm 1.02)$ & 55 & 8 \\
\hline$\%$ SW3 & $<0.01(+)$ & 0.041 & $<0.01$ & $-0.99( \pm 0.94)$ & 38 & 23 \\
\hline$\%$ SUM & $0.21(-)$ & $<0.001$ & 0.60 & $-6.51( \pm 3.37)$ & 6 & 50 \\
\hline
\end{tabular}

Notes: Models predict the proportions of individuals with particular categories of biological traits (\%TRAIT, see Methods for codes) from reach hydraulics (FR, the Froude number, used as covariate) and continent (used as categorical variable). "Continent effect" indicates whether the effect of continent is significant (in cases where $P<0.05$, a " + " indicates higher trait values in Virginia than in France, while a "-" indicates higher trait proportions in France). "FR effect" indicates whether the effect of FR is significant (i.e., the intercontinental slope $S_{2}$, which reflected the mean effect of FR in the two continents, differed from 0 after sequential Bonferroni correction; boldface). "FR $\times$ Continent" indicates whether $S_{2}$ interacted with continent (cases where $P<0.05$ ). $S_{2}$ is reported with its $95 \%$ confidence interval. "Variance continent" is the percentage of variance explained by continent alone. "Variance FR" is the percentage of within-continent variance explained by FR. In column "\%TRAIT," traits are boldface for which $S_{2}$ differed from 0 and did not interact with continent (i.e., cases where convergence was observed).

\section{Testing for reach-scale community convergence across continents}

Covariance analyses indicated strong support for convergence of community traits across continents for both FR (Table 3) and \%POOL (Table 4). All six traits examined and the summary variable (\%SUM) were comparably related, in the two continents, to at least one of the two habitat variables (bolded traits in Tables 3 and 4). Convergence under the variable FR was supported for the proportions of large, fecund, and longlived fish (\%BL3, \%FE3, \%MA4; Table 3), and for the summary variable $\%$ SUM. Convergence under the variable \%POOL was supported for all trait variables except the proportion of large species (\%BL3), which showed a nonsignificant slope (Table 4).

The effect of zoogeography on community trait composition was also significant for all individual biological variables except the proportion of nonbenthic species (\%VP2, when FR was used as covariate in the models), as indicated by the $P$ values for the continent effect in Tables 3 and 4. In particular, communities in France had larger and longer-lived fish (see signs associated with the continent effect in Tables 3 and 4). To a lesser extent, fish in France were also more streamlined, more fecund, and better swimmers. Continent explained between 4 and $55 \%$ of the variance in trait proportions (Tables 3 and 4), which was similar to the range of within-continent variance explained by FR (1$54 \%$; Table 3), but greater than that explained by $\%$ POOL (0-26\%; Table 4).

Both tests involving the summary variable, \%SUM, (Tables 3 and 4) indicated convergence. \%SUM differed between continent when using \%POOL as the habitat descriptor, but not when using FR. The variance of \%SUM was less explained by continent than by our habitat descriptors $(50 \%$ of the within-continent variance was explained by FR, $23 \%$ was explained by $\%$ POOL; Tables 3 and 4). These results suggested that

TABLE 4. Results of covariance models (model 3 in Methods) tested in reaches of France ( $n$ $=11)$ and Virginia $(n=76)$.

\begin{tabular}{lcrcccc}
\hline \hline \%TRAIT & $\begin{array}{c}\text { Continent } \\
\text { effect } P\end{array}$ & $\begin{array}{c}\text { \%POOL } \\
\text { effect } P\end{array}$ & $\begin{array}{c}\text { \%POOL } \times \\
\text { continent }\end{array}$ & \multicolumn{1}{c}{$S_{3}$} & $\begin{array}{c}\text { Variance } \\
\text { continent }\end{array}$ & $\begin{array}{c}\text { Variance } \\
\% \text { POOL }\end{array}$ \\
\hline \%BL3 & $<0.01(-)$ & 0.493 & 0.26 & $0.05( \pm 0.15)$ & 51 & 0 \\
\%FE3 & $<0.01(-)$ & $\mathbf{0 . 0 3 6}$ & 0.06 & $0.11( \pm 0.10)$ & 19 & 5 \\
\%MA4 & $<0.01(-)$ & $<\mathbf{0 . 0 0 1}$ & 0.88 & $0.48( \pm 0.18)$ & 27 & 26 \\
\%VP2 & $0.04(-)$ & $\mathbf{0 . 0 2 2}$ & 0.96 & $0.24( \pm 0.20)$ & 4 & 5 \\
\%SH1 & $<0.01(+)$ & $\mathbf{0 . 0 0 7}$ & 0.88 & $0.24( \pm 0.18)$ & 12 & 8 \\
\%SW3 & $<0.01(+)$ & $\mathbf{0 . 0 0 5}$ & 0.34 & $0.27( \pm 0.19)$ & 14 & 9 \\
\%SUM & $<0.01(-)$ & $<\mathbf{0 . 0 0 1}$ & 0.73 & $1.40( \pm 0.56)$ & 12 & 23 \\
\hline
\end{tabular}

Notes: Models predict the proportions of individuals with particular categories of biological traits from the geomorphology of reaches (\%POOL, used as a covariate) and continent (used as a categorical variable). Columns and codes are similar to Table 3, but with \%POOL instead of FR as the covariate. In column "\%TRAIT," traits are boldface for which convergence was observed. 


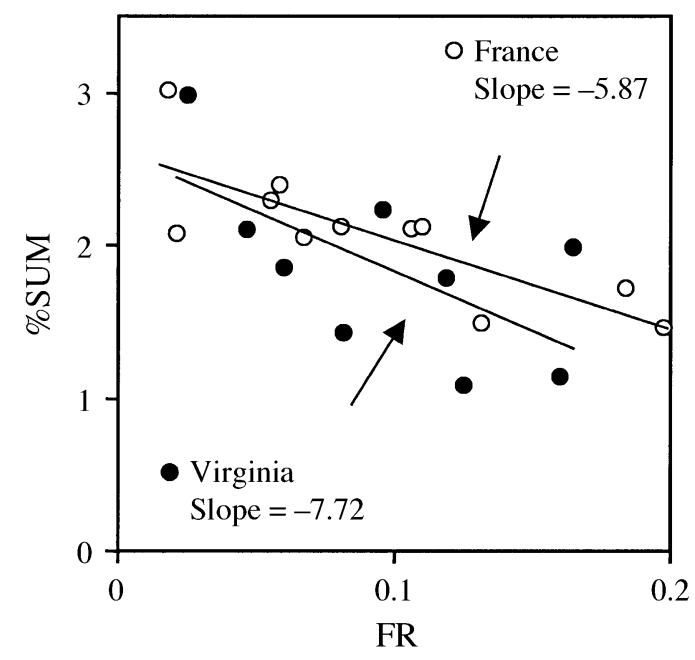

FIG. 2. Linear relationships between the synthetic biological variable \%SUM and hydraulics of reaches described by FR (see Methods: Methodological framework for variable definitions). Relationships are provided for reaches of France $(n=11)$ and Virginia $(n=9)$ where hydraulics were described. Slopes do not differ statistically and are different from 0 (the intercontinental slope is -6.51 ; see Table 3 ).

FR could be a more general predictor of aggregate community traits than \% POOL.

As between continents, convergence along geomorphic gradients was observed across the five basins considered. When reaches were grouped by basin instead of continent in model 3 , \% POOL had a comparable effect on $\%$ SUM within basins (slope $\mathrm{S}_{3}=1.23$, not interacting with basin $[P=0.56]$, significantly different from $0[P<0.001])$. Basin explained $25 \%$ of the variance of $\%$ SUM; $\%$ POOL explained $22 \%$ of its variance within basins. Notably, basin explained twice as much variance in \%SUM as did continent (see Table 4). Given that only one basin was represented in France, this suggests that the variation in trait proportions among Virginia basin is comparable in magnitude to the variation between France and Virginia.

Overall, covariance analyses at the reach scale supported convergence in 8 of 12 tests made for individual traits, in the two tests involving \%SUM, and revealed strong effects of continent and basin on community traits. Linear relationships between \%SUM and FR (Fig. 2) or \% POOL (Fig. 3) in France, in Virginia, and in basins of Virginia where most reaches were situated confirmed that the effect of hydraulics and geomorphology on biological traits in the different continents was comparable. Our findings illustrate the weaker influence of continent on regression intercepts when using FR as habitat descriptor (Fig. 2). Linear relationships between the proportion of large species \%BL3 and FR in the two continents illustrate both intercontinental differences, and the comparable relationships with FR within continents (Fig. 4).

In cases where intercontinental convergence was ob- served (bolded traits in Tables 3 and 4), it was always qualitatively predicted from observations of fish preferences at the local scale in France, as indicated by the consistent negative signs of $S_{1}$ and $S_{2}$ in Tables 2 and 3. $S_{3}$ had positive signs for all traits in Table 4 , as expected given the negative correlation between FR and \%POOL. In other words, reaches dominated by pools and/or with low Froude number contain high proportions of individuals that are nonbenthic, large, fecund, long-lived, nonstreamlined, and weak swimmers. In addition, reach-scale observations of traits were consistent with quantitative, local-scale predictions of the effects of FR on traits in seven out of eight cases. Specifically, $S_{1}$ values (Table 2 ) fell in the $95 \%$ confidence intervals observed for $S_{2}$ (Table 3 ) in all cases where convergence was observed. Further, the quantitative linear relation between the two habitat descriptors $\left(\mathrm{FR}=-0.30[\% \mathrm{POOL}]+0.30 ; r^{2}=0.55, P<\right.$ $0.01, n=20$ ) implied that the effect of $\%$ POOL on traits (described by $S_{3}$ ) should scale as $-0.3 S_{1}$. Again, $-0.3 S_{1}$ fell in the confidence intervals observed for $S_{3}$ (Table 4) in all cases except one (the proportion of weak swimmers, \%SW3).

In cases where intercontinental convergence was observed, the confidence intervals obtained for the quantitative effects of habitat variables on individual biological traits were generally large at the reach scale ( $\pm 37 \%$ to $\pm 91 \%$ of uncertainty around significant slopes in Tables 3 and 4). Observations at the reach scale did not contradict our quantitative predictions based on local-scale preference models; rather they confirmed that their order of magnitude was correct. Thus, we could not test the capacity of scaled-up models to provide precise estimates of the effect of habitat on individual traits. However, for the composite trait $\%$ SUM, confidence intervals were among the smaller, $\pm 52 \%$ for FR $\left(S_{2}\right.$; Table 3$)$ and $\pm 40 \%$ for $\%$ POOL $\left(S_{3}\right.$; Table 3$)$. For this synthetic trait variable, quantitative predictions of the effects of hydraulics and geomorphology were very close to what we observed. For FR, the observed $\left(S_{2}\right)$ and predicted $\left(S_{1}\right)$ values were -6.51 and -4.55 , respectively; for \%POOL, the observed $\left(S_{3}\right)$ and predicted $\left(-0.3 S_{1}\right)$ values were 1.40 and 1.37 , respectively.

\section{Discussion}

Our goals were to test whether fish community traits on two continents converge along hydraulic and geomorphic gradients, and to see if this reach-scale convergence could be predicted from fish preference studies conducted at the local scale in France. The major strength of these tests is that they address some limits of current convergence analyses. We tested a priori quantitative predictions based on an identified process (microhabitat choice by species within reaches), using quantitative descriptions of the environment (proportion of pools vs. riffles and Froude number of reaches). Tests were made in contrasting sets of streams in France 

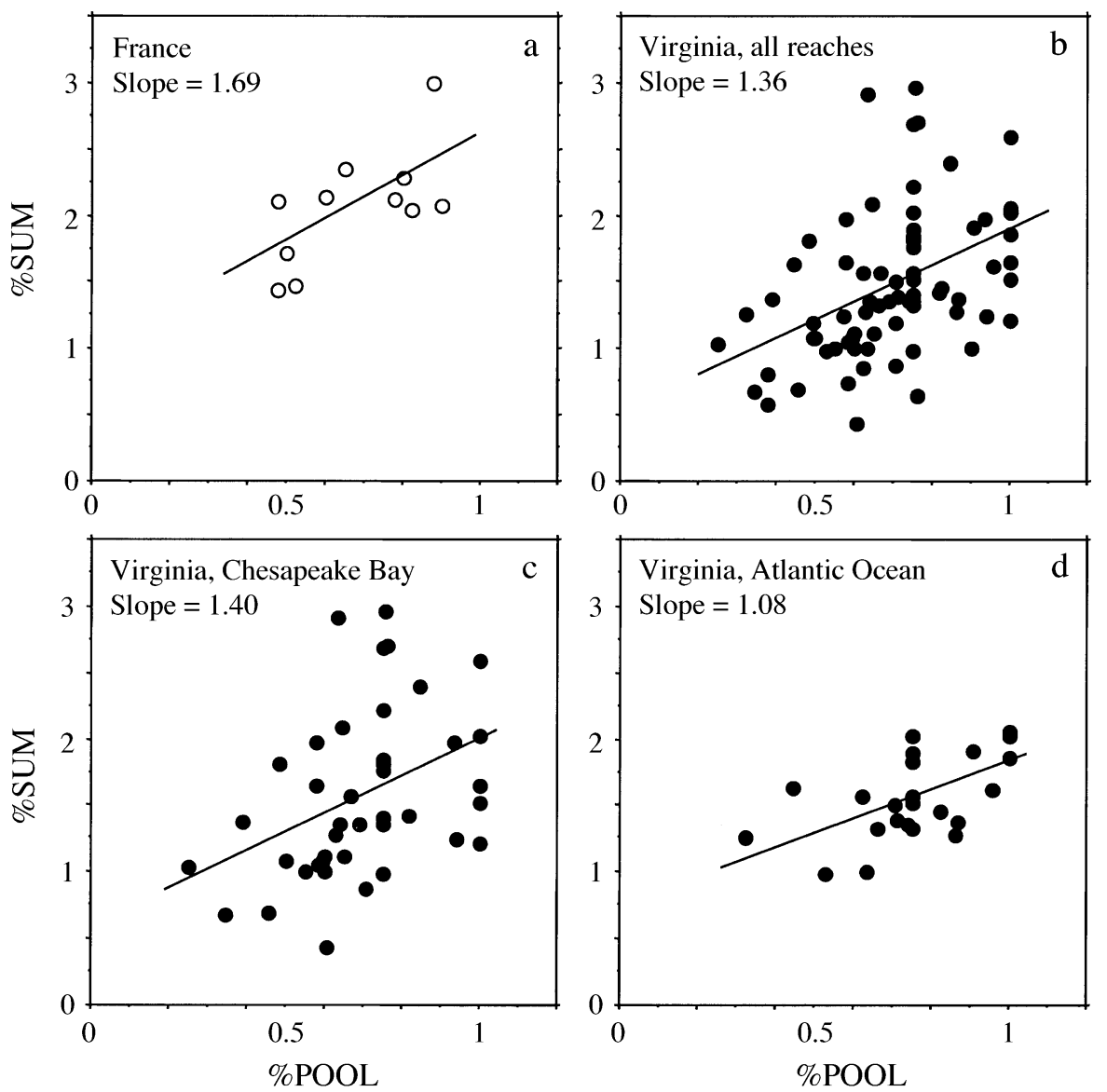

FIG. 3. Linear relationships between the synthetic biological variable \%SUM and the geomorphology of reaches described by \%POOL (see Methods: Methodological framework for variable definitions). Relationships are provided for reaches of France $(\mathrm{a} ; n=11)$, Virginia ( $\mathrm{b} ; n=76$ ), and subsets of Virginia reaches situated in the two basins with the most samples (c; $n=41 ; \mathrm{d} ; n=25$ ). Slopes do not differ statistically and are different from 0 (the intercontinental slope is 1.4 ; see Table 4).

(11 reaches) and Virginia (76 reaches), largely independent from the streams used to generate the predictions.

Our reach-scale convergence analyses demonstrated (1) a strong effect of the continent on species-trait proportions in fish communities, and (2) that geomorphology and hydraulics of reaches (which were correlated) shape community traits comparably across the two continents, as well as across large basins. Therefore, despite their continental dissimilarities (and though our trait descriptions were limited in scope and precision), lotic fish communities of France and Virginia are convergent in their relationships with geomorphology and hydraulics. These patterns were observed even though only one species was common to France and Virginia (most species were of different genera and families).

Convergence at the reach scale confirmed qualitatively and quantitatively our blind predictions in most cases. This indicated some success in scaling-up localscale habitat preferences to reach-scale community

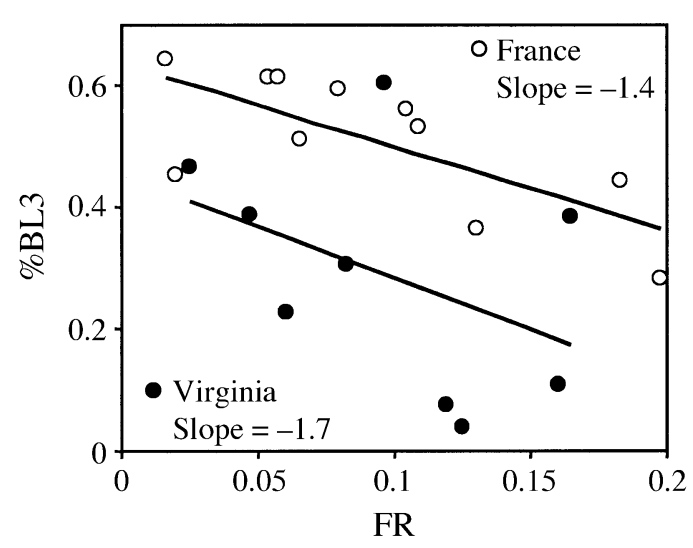

FIG. 4. Linear relationships between the proportion of large fish \%BL3 and FR (see Methods: Methodological framework for variable definitions). Relationships are provided for reaches of France $(n=11)$ and Virginia $(n=9)$. Though fish are larger in France, slopes do not differ statistically and are different from 0 (the intercontinental slope is -1.48 ; see Table 3 ). Note that, on average, an increase in FR by 0.2 can divide by 2 the proportion of large fish. 
characterizations, despite large uncertainty around quantitative estimates of the effects of hydraulics and geomorphology at the reach scale. Although the variance in trait variables explained by the habitat variables at the local scale was generally low $(<5.8 \%)$, trends in microhabitat preferences were very significant $(15$ out of 18 tests were successful) and, when extrapolated to the reach scale, they explained an important proportion of variance in trait variables (up to $55 \%$ of the variability in individual species-trait proportions). Therefore, our results confirm that highly variable local-scale features can be used to predict patterns observed on larger scales (Levin 1992, Peckarsky et al. 1997).

\section{Hierarchical filters for species traits}

At the stream-reach scale, zoogeography (continent or basin) explained up to $55 \%$ of the variability in individual species-trait proportions in the communities we studied. In particular, fish in France were larger, lived longer, and were more streamlined than those in Virginia. Furthermore, our synthetic description of trait proportions (\%SUM) varied among basins in Virginia as it did between continents. Observed dissimilarities between fish communities of the two continents may, in part, reflect differences in stream size (French streams were larger). However, they are concordant with previous observations of differences in fish communities between Europe and eastern North America, which have distinct evolutionary histories (Mahon 1984, Moyle and Herbold 1987). Major basins in Virginia also have different evolutionary histories, which have produced distinctive fish assemblages (Hocutt and Wiley 1986, Angermeier and Winston 1999). Beyond these historical and evolutionary differences, fish communities are affected by a series of environmental filters at hierarchical spatial scales (Poff 1997, Angermeier and Winston 1998). Agents of these filters are numerous, e.g., temperature, water quality, nutrient availability, and dispersal barriers. As a result, fish communities vary greatly among stream reaches, as for example along longitudinal gradients of stream size. Given our incomplete knowledge of fish autoecology, functional descriptions of communities only partly account for these dissimilarities (Angermeier and Winston 1999, Lamouroux et al. 1999b).

Our analyses suggest that reach-scale geomorphology and hydraulics are critical filters that regulate community structure. For example, hydraulic/geomorphic constraints probably place a premium on large body size (predator avoidance) and nonbenthic lifestyle (foraging from surface) in pools, and on species morphologically adapted to high shear stresses in riffles. Even though our habitat descriptors are static, they reflect habitat diversity within reaches (see Lamouroux et al. $1992,1995)$ that can be particularly important in low flow (high density) conditions (Wiens 1977, Lamouroux et al. 1999b) and are well suited to capture im- portant variation in fish species traits. However, other forces are also expected to drive selection for traits, explaining why our physical variables do not account for most variance in community traits within continents. These forces might include temporal environmental variability (Poff and Allan 1995, Grossman et al. 1998), winter mortality, or ontogenic shifts in predator avoidance or feeding characteristics (Schlosser 1987, Schlosser and Ebel 1989).

\section{Geomorphology and hydraulics: a template for species traits}

Given the simple physical variables we used to characterize habitat, the snapshot fish data in Virginia, and the multiplicity of environmental filters affecting fish traits at hierarchical spatial scales, the significance of most of our tests demonstrates a strong effect of our habitat variables on community structure. Proportional representation of each trait was related, comparably in the two continents, to at least one of our habitat variables (geomorphology or hydraulics, 8 of 12 tests indicating convergence). Notably, reach-scale analyses confirmed qualitatively our a priori predictions in all cases, and quantitatively in seven of these eight successful tests. In other words, reaches dominated by pools and/or with low Froude number in a given region contain relatively high proportions of individuals that are nonbenthic, large, fecund, long-lived, unstreamlined, and weak swimmers. Once the continent effect was removed, hydraulics explained from $1 \%$ to $54 \%$, and geomorphology $0 \%$ to $26 \%$, of the variance in proportions of individual traits. For a composite variable describing all traits, these two habitat descriptors explained $50 \%$ and $25 \%$, respectively.

A more complete comparison of the predictive power of hydraulics versus geomorphology would use similar sample sizes. Despite smaller sample size, the Froude number appeared to be a better predictor of fish traits than geomorphology. The Froude number is a more objective variable because the proportions of pools, runs, and riffles observed in streams can vary among observers and discharge rates. However, because both variables are correlated, it is difficult to interpret differences in their predictive power. Longevity was the biological trait best predicted by our two physical variables. Among other traits, size and fecundity were the traits better predicted from Froude number, whereas shape and swimming factor were the traits better predicted from geomorphology. These traits are slightly intercorrelated and it is difficult to sort out which one(s) may be driving the others evolutionarily.

Overall, fish traits related to our physical variables reflect morphological and behavioral adaptation to the environment. Species that use mostly pool-type habitats may experience weaker selective pressures for being streamlined, small, benthic, or strong swimmers, as they do not experience continuous high shear stresses. They can also favor reproduction in their energetic 
tradeoffs. Similarly, fish using slow-flowing biotopes tend to be deep bodied (Gatz 1979), and larger fish are found in reaches with lower Froude number in incised channels (Shields et al. 1994). Greater fecundity and longevity in reaches with pools can be partly due to a positive correlation with size (Wooton 1990), or to lower survival rate of eggs laid in slow-flowing habitats. There are potential similarities between our observations of community traits-habitat relationships, and individual traits-habitat evolution during ontogenesis. For example, the hydrodynamics of shape and the swimming capacities of grayling (Thymallus thymallus) increase during ontogenesis while its habitat preference shifts towards high velocities (Sagnes et al. 1997, 2000). More generally, the strong influence of geomorphology on lotic and riparian communities has been observed in local studies of fish, benthic invertebrates, plants, and amphibians (Schlosser 1982, Huryn and Wallace 1987, Harris 1988, Statzner et al. 1988, Angradi 1996, Grubaugh et al. 1996, Kupferberg 1996).

The potential for morphological traits (size, shape) to reflect adaptations to physical habitat is not unique to fish. Despite the contrasting results of previous convergence analyses for different kinds of organisms, convergence of morphological traits across continents and related to habitat features has also been observed for birds, lizards, and plants (Schluter 1986, Myers and Giller 1988). In this context, our methodology (based on covariance analyses), which accounts for zoogeographic filters while assessing effects of quantitative habitat features on morphological traits, may be applicable to convergence studies for a wide range of taxa.

\section{Implications for predictive models in community ecology}

Our study supports the existence of habitat templates for ecological strategies (Southwood 1977, Poff and Ward 1990, Resh et al. 1994), because it reveals general links between habitat features and biological traits in fish communities. Scaling the habitat template axes by quantifying important habitat variables for ecological traits is not easy, because spatial and temporal habitat axes can be defined in many ways. Estimates of habitat diversity depend on the scale considered, the variables involved, and their statistical treatment. Our results suggest that it is possible, at least for running water systems, to identify key quantitative descriptors of the habitat that generally influence species traits in different basins or continents. However, these results explain a limited portion of community structure variability. Future models could include more complete or precise trait descriptions for species, as well as other environmental variables describing hydrological variability or channel characteristics. Such developments would contribute to more precise definitions for habitat template axes, which are needed to enhance predictive power and general usefulness in community ecology. Because our predictions were based on observations of individuals, their validation supports the notion of extrapolating from individual behavior to community patterns (Peckarsky et al. 1997). Identifying the circumstances under which such extrapolations do and do not succeed can improve our general understanding of community organization.

Our results also support multidisciplinary approaches to ecology. Our best predictor of species traits was a simple hydraulic variable, the Froude number, which is dimensionless. Dimensionless variables are largely used in physics, engineering, and ecology, as they govern energetic similitude among unrelated systems (Charnov and Berrigan 1991, Yalin 1992). For example, physical-scale models built for experimentation have the same dimensionless characteristics as the corresponding real system. In our study, streams of France and Virginia had similar ranges of Froude numbers, even though reaches in Virginia were generally narrower, shallower and slower flowing (see Methods). This variable also integrates the spatial diversity of point hydraulic variables (bottom shear stress, current velocity) in stream reaches (Lamouroux et al. 1992, 1995). Therefore, our results indicate that dimensionless physical variables reveal common properties of systems of different sizes, and are potential predictors of ecological similarities in these systems (Statzner et al. 1988, Heede and Rinne 1990). Using dimensionless descriptions of the habitat could be ecologically instructive in a wide range of systems strongly influenced by physical factors (e.g., temperature, fire, desiccation, or windshear).

In the context of numerous hierarchical influences on community characteristics, convergence analyses between continents are efficient tools to understand the relative influence of historical and environmental processes affecting communities. Convergence can be studied using several characteristics of communities (e.g., functional attributes, assembly rules, species richness), each of which may indicate the importance of various abiotic constraints and biotic interactions (Schluter 1986). Here, we focused on functional attributes because species richness was so different in our data sets that other community characteristics would be hardly comparable in the two continents. In addition, we could derive a priori predictions concerning convergence of community traits. More generally, however, studies testing the general influence of quantitative variables on various community characteristics in unrelated systems can provide sound bases for improving theories of community organization. Given that most attempts to quantify relationships between habitat and communities have focused on statistical correlation among large sets of variables, more effort should be made to develop and test simple, mechanistically based models that can be both predictive and generally applicable (Horwitz 1978, Schlosser 1982, Poff 1997). Correlative analyses alone may statistically 
explain a large portion of community variation across sites, but, by failing to identify the factors responsible for community patterns, they have low predictive power. The current development of large data sets in ecology (Gurevitch and Hedges 1999) encourages the testing of predictive quantitative models of convergence. These are essential tools to discover which aspects of communities are predictable from their environment despite the strong natural variability in community characteristics.

\section{ACKNOWLEDGMENTS}

The university association ARALEPBP and the River Ecology Group at the University Lyon 1 contributed to collect fish in France. Financial support came from the Compagnie Nationale du Rhône (CNR), Electricité de France (EDF), and the Agence de l'Eau Rhône-Méditerranée-Corse. N. Lamouroux received financial support from the Colorado State University to work in the USA for this project. S. L. Kohler, W. M. Tonn, B. Hugueny, B. Statzner, J. Olden, G. D. Grossman, and anonymous referees provided helpful comments on earlier versions of the manuscript. All of this help is gratefully acknowledged.

\section{Literature Cited}

Angermeier, P. L. 1995. Ecological attributes of extinctionprone species: loss of freshwater fishes in Virginia. Conservation Biology 9:143-158.

Angermeier, P. L., and M. R. Winston. 1998. Local vs. regional influences on local diversity in stream fish communities of Virginia. Ecology 79:911-922.

Angermeier, P. L., and M. R. Winston. 1999. Characterizing fish community diversity across Virginia landscapes: prerequisite for conservation. Ecological Applications 9:335349.

Angradi, T. R. 1996. Inter-habitat variation in benthic community structure, function, and organic matter storage in 3 Appalachian headwater streams. Journal of the North American Benthological Society 15:42-63.

Bastow, W. J., A. D. Q. Agnew, and T. R. Partridge. 1994. Carr texture in Britain and New Zealand: community convergence compared with a null model. Journal of Vegetation Science 5:109-116.

Bovee, K. D. 1982. A guide to stream habitat analysis using the instream flow incremental methodology. Instream Flow Information Paper 12. U.S. Fish and Wildlife Service, Fort Collins, Colorado, USA.

Charnov, E. L., and D. Berrigan. 1991. Dimensionless numbers and the assembly rules for life histories. Philosophical Transactions of the Royal Society of London B332:41-48.

Dunne, T., and L. B. Leopold. 1978. Water in environmental planning. W. H. Freeman, San Francisco, California, USA.

Gatz, A. J. 1979. Ecological morphology of freshwater stream fishes. Tulane Studies in Zoology and Botany 21: 91-124.

Gordon, N. D., T. A. McMahon, and B. L. Finlayson. 1992. Stream hydrology. An introduction for ecologists. John Wiley and Sons, New York, New York, USA.

Gorman, O. T., and J. R. Karr. 1978. Habitat structure and stream fish communities. Ecology 59:507-515.

Grossman, G. D., R. E. Ratajczak, Jr., M. Crawford, and M. C. Freeman. 1998. Assemblage organization in stream fishes: effects of environmental variation and interspecific interactions. Ecological Monographs 68:395-420.

Grubaugh, J. W., J. B. Wallace, and E. S. Houston. 1996. Longitudinal changes of macroinvertebrate communities along an Appalachian stream continuum. Canadian Journal of Fisheries and Aquatic Sciences 53:896-909.
Gurevitch, J., and L. V. Hedges. 1999. Statistical issues in ecological meta-analyses. Ecology 80:1142-1149.

Harris, R. R. 1988. Associations between stream valley geomorphology and riparian vegetation as a basis for landscape analysis in the eastern Sierra Nevada, California, USA. Environmental Management 12:219-228.

Hart, D. D., and C. M. Finelli. 1999. Physical-biological coupling in streams: the pervasive effects of flow on benthic organisms. Annual Reviews of Ecology and Systematics 30:363-395.

Heede, B. H., and J. N. Rinne. 1990. Hydrodynamic and fluvial morphologic processes: implications for fisheries management and research. North American Journal of Fisheries Management 10:249-268.

Hocutt, C. H., and E. O. Wiley, editors. 1986. The zoogeography of North American freshwater fishes. John Wiley and Sons, New York, New York, USA.

Horwitz, R. J. 1978. Temporal variability patterns and the distributional patterns of stream fishes. Ecological Monographs 48:307-321.

Huryn, A. D., and J. B. Wallace. 1987. Local geomorphology as a determinant of macrofaunal production in a mountain stream. Ecology 68:1932-1942.

Inouye, R. S., and D. Tilman. 1995. Convergence and divergence of old-field vegetation after $11 \mathrm{yr}$ of nitrogen addition. Ecology 76:1872-1887.

Jenkins, R. E., and N. M. Burkhead. 1994. Freshwater fishes of Virginia. American Fisheries Society, Bethesda, Maryland, USA.

Jowett, I. G. 1993. A method for objectively identifying pool, run, and riffle habitats from physical measurements. New Zealand Journal of Marine and Freshwater Research 27: 241-248.

Knighton, D. 1998. Fluvial forms and processes: a new perspective. John Wiley and Sons, New York, New York, USA.

Kupferberg, S. J. 1996. Hydrologic and geomorphic factors affecting conservation of a river-breeding frog (Rana boylii). Ecological Applications 6:1332-1344.

Lamouroux, N., H. Capra, M. Pouilly, and Y. Souchon. 1999a. Fish habitat preferences at the local scale in large streams of southern France. Freshwater Biology 42:673-687.

Lamouroux, N., J. M. Olivier, H. Persat, M. Pouilly, Y. Souchon, and B. Statzner. 1999b. Predicting community characteristics from habitat conditions: fluvial fish and hydraulics. Freshwater Biology 42:1-25.

Lamouroux, N., Y. Souchon, and E. Hérouin. 1995. Predicting velocity frequency distributions in stream reaches. Water Resources Research 31:2367-2375.

Lamouroux, N., B. Statzner, U. Fuchs, F. Kohmann, and U. Schmedtje. 1992. An unconventional approach to modeling spatial and temporal variability of local shear stress in stream segments. Water Resources Research 28:32513258.

Lee, D. S., C. R. Gilbert, C. H. Hocutt, R. E. Jenkins, D. E. McAllister, and J. R. Stauffer, Jr. 1980. Atlas of North American freshwater fishes. North Carolina State Museum of Natural History, Raleigh, North Carolina, USA.

Leftwich, K. N., P. L. Angermeier, and C. A. Dolloff. 1997. Factors influencing behavior and transferability of habitat models for a benthic stream fish. Transactions of the American Fisheries Society 126:725-734.

Levin, S. A. 1992. The problem of pattern and scale in Ecology. Ecology 73:1943-1967.

Magnuson, J. J., W. M. Tonn, A. Banerjee, J. Toivonen, O. Sanchez, and M. Rask. 1998. Isolation vs. extinction in the assembly of fishes in small northern lakes. Ecology 79: 2941-2956.

Mahon, R. 1984. Divergent structure in fish taxocenese of north temperate streams. Canadian Journal of Fisheries and Aquatic Sciences 41:330-350. 
Mérigoux, S. 1998. Variabilité spatio-temporelle de l'environnement et structure des peuplements de juvéniles de poissons: cas d'un fleuve intertropical soumis à un aménagement hydroélectrique. Dissertation. Université claude Bergnard-Lyon 1, Villeurbanne, France.

Michel, P., and T. Oberdorff. 1995. Feeding habits of fourteen European freshwater fish species. Cybium 19:5-46.

Moyle, P. B., and B. Herbold. 1987. Life-history patterns and community structure in stream fishes of western North America: comparisons with eastern North America and Europe. Pages 25-32 in W. J. Matthews and D. C. Heins, editors. Community and evolutionary ecology of North American stream fishes. University of Oklahoma Press, Oklahoma, USA.

Myers, A. A., and P. S. Giller. 1988. Analytical biogeography. Chapman and Hall, New York, New York, USA.

Newbury, R., and M. Gaboury. 1993. Exploration and rehabilitation of hydraulic habitats in streams using principles of fluvial behaviour. Freshwater Biology 29:195-210.

Oberdorff, T., J. F. Guégan, and B. Hugueny. 1995. Global scale patterns of fish species richness in rivers. Ecography 18:345-352.

Page, L. M., and B. M. Burr. 1991. A field guide to freshwater fishes: North America north of Mexico. Houghton Mifflin, Boston, Massachusetts, USA.

Peckarsky, B. L., S. D. Cooper, and A. R. McIntosh. 1997. Extrapolating from individual behavior to populations and communities in streams. Journal of the North American Benthological Society 16:375-390.

Persat, H., and G. H. Copp. 1990. Electric fishing and point abundance sampling for the ichthyology of large rivers. Pages 197-209 in I. G. Cowx, editor. Developments in electric fishing. Fishing News Books, Cambridge University Press, Cambridge, UK.

Persat, H., J. M. Olivier, and D. Pont. 1994. Theoretical habitat templets, species traits, and species richness: fish in the Upper Rhône river and its floodplain. Freshwater Biology 31:439-454.

Peters, R. H. 1991. A critique for ecology. Cambridge University Press, Cambridge, UK.

Poff, N. L. 1997. Landscape filters and species traits: towards mechanistic understanding and prediction in stream ecology. Journal of the North American Benthological Society 16:391-409.

Poff, N. L., and J. D. Allan. 1995. Functional organization of stream fish assemblages in relation to hydrological variability. Ecology 76:606-627.

Poff, N. L., and J. V. Ward. 1990. Physical habitat template of lotic systems: recovery in the context of historical pattern of spatiotemporal heterogeneity. Environmental Management 14:629-645.

Resh, V. H., A. G. Hildrew, B. Statzner, and C. R. Townsend. 1994. Theoretical habitat templets, species traits, and species richness: a synthesis of long-term research on the Upper Rhône River in the context of currently developed ecological theory. Freshwater Biology 31:539-554.

Sagnes, P., J.-Y. Champagne, and R. Morel. 2000. Shifts in drag and swimming potential during grayling ontogenesis: relations with habitat use. Journal of Fish Biology 57:5268.

Sagnes, P., P. Gaudin, and B. Statzner. 1997. Shifts in morphometrics and their relation to hydrodynamic potential and habitat use during grayling ontogenesis. Journal of Fish Biology 50:846-858.

Samuels, C. L., and J. A. Drake. 1997. Divergent perspectives on community convergence. Trends in Ecology and Evolution 12:427-432.

Schlosser, I. J. 1982. Fish community structure and function along two habitat gradients in a headwater stream. Ecological Monographs 52:395-414.

Schlosser, I. J. 1987. The role of predation in age- and sizerelated habitat use by stream fishes. Ecology 68:651-659.

Schlosser, I. J., and K. K. Ebel. 1989. Effects of flow regime and cyprinid predation on a headwater stream. Ecological Monographs 59:41-57.

Schluter, D. 1986. Tests for similarity and convergence of finch communities. Ecology 67:1073-1085.

Shields, F. D., Jr., S. S. Knight, and C. M. Cooper. 1994. Effects of channel incision on base flow stream habitats and fishes. Environmental Management 18:43-57.

Sokal, R. R., and F. J. Rohlf. 1998. Biometry: the principles and practice of statistics in biological research. W. H. Freeman, New York, New York, USA.

Southwood, T. R. E. 1977. Habitat, the templet for ecological strategies? Journal of Animal Ecology 46:337-365.

Statzner, B., J. A. Gore, and V. H. Resh. 1988. Hydraulic stream ecology: observed patterns and potential applications. Journal of the North American Benthological Society 7:307-360.

Terofal, F. 1987. Les poissons d'eau douce. Solar, Paris, France.

Thévenet, A., and B. Statzner. 1999. Linking fluvial fish community to physical habitat in large woody debris: sampling effort, accuracy and precision. Archiv für Hydrobiologie 145:57-77.

Tonn, W. M., J. J. Magnuson, M. Rask, and J. Toivonen. 1990. Intercontinental comparison of small-lake fish assemblages: the balance between local and regional processes. American Naturalist 136:345-375.

Townsend, C. R., and A. G. Hildrew. 1994. Species traits in relation to a habitat templet for river systems. Freshwater Biology 31:265-275.

Vadas, R. L., Jr., and D. J. Orth. 1993. A new technique for estimating the abundance and habitat use of stream fishes. Journal of Freshwater Ecology 8:305-317.

Verneaux, J. 1981. Les poissons et la qualité des cours d'eau. Annales Scientifiques de 1'Université de Franche-Comté Besançon, Biologie Animale, 4ème série, Fascicule 2:3341.

Wiens, J. A. 1977. On competition in variable environments. American Scientist 65:590-597.

Wiens, J. A. 1991. Ecological similarity of shrub-desert avifaunas of Australia and North America. Ecology 72:479495.

Wootton, R. J. 1990. Ecology of teleost fishes. Fish and fisheries series 1. Chapman and Hall, New York, New York, USA.

Yalin, M. S. 1992. River mechanics. Pergamon, New York, New York, USA. 
APPENDIX: Species traits.

\begin{tabular}{|c|c|c|c|c|c|c|c|c|c|}
\hline \multirow[b]{2}{*}{ Country } & \multirow[b]{2}{*}{ Family } & \multirow[b]{2}{*}{ Species } & \multirow[b]{2}{*}{ Common name } & \multicolumn{6}{|c|}{ Biological traits } \\
\hline & & & & $\mathrm{BL}$ & FE & MA & VP & & SW \\
\hline \multirow[t]{14}{*}{ France } & Anguillidae & Anguilla anguilla & eel & 3 & 3 & 4 & 2 & 4 & 3 \\
\hline & Cyprinidae & Alburnoides bipunctatus & schneider & 2 & 2 & 3 & 2 & 2 & 1 \\
\hline & & Alburnus alburnus & bleak & 2 & 2 & 3 & 2 & 3 & 1 \\
\hline & & Barbus barbus & barbel & 3 & 2 & 4 & 1 & 3 & 1 \\
\hline & & Chondrostoma nasus & nase & 3 & 2 & 4 & 2 & 3 & 1 \\
\hline & & Gobio gobio & gudgeon & 2 & 2 & 3 & 1 & 3 & 1 \\
\hline & & Leuciscus cephalus & chub & 3 & 2 & 4 & 2 & 3 & 1 \\
\hline & & Leuciscus leuciscus & dace & 2 & 2 & 3 & 2 & 3 & 1 \\
\hline & & Leuciscus souffia & blageon & 2 & 2 & 3 & 2 & 3 & 1 \\
\hline & & Phoxinus phoxinus & minnow & 1 & 1 & 2 & 2 & 3 & 1 \\
\hline & & Rutilus rutilus & roach & 3 & 3 & 4 & 2 & 2 & 1 \\
\hline & Cobitidae & Barbatula barbatula & stone loach & 2 & 2 & 3 & 1 & 4 & 2 \\
\hline & Centrarchidae & Lepomis gibbosus & pumpkinseed & 2 & 2 & 4 & 2 & 1 & 2 \\
\hline & Percidae & Perca fluviatilis & perch & 3 & 3 & 4 & 2 & 2 & 1 \\
\hline \multirow[t]{55}{*}{ USA (Virginia) } & Petromyzontidae & Ichthyomyzon greeleyi & mountain brook lamprey & 2 & -9 & 3 & 1 & 4 & 3 \\
\hline & & Lampetra aepyptera & least brook lamprey & 2 & 2 & 3 & 1 & 4 & 3 \\
\hline & & Lampetra appendix & American brook lamprey & 2 & 2 & 4 & 1 & 4 & 3 \\
\hline & & Petromyzon marinus & sea lamprey & 3 & 3 & 4 & 1 & 4 & 3 \\
\hline & Anguillidae & Anguilla rostrata & American eel & 3 & 3 & 4 & 2 & 4 & 3 \\
\hline & Esocidae & Esox americanus & redfin pickerel & 2 & 1 & 3 & 2 & 4 & 1 \\
\hline & & Esox niger & chain pickerel & 3 & 2 & 4 & 2 & 4 & 1 \\
\hline & Umbridae & Umbra pygmaea & eastern mudminnow & 2 & 1 & 2 & 2 & 2 & 3 \\
\hline & Cyprinidae & Campostoma anomalum & central stoneroller & 2 & 2 & 3 & 1 & 3 & 2 \\
\hline & & Clinostomus funduloides & rosyside dace & 2 & 1 & 3 & 2 & 3 & 1 \\
\hline & & Cyprinella analostana & satinfin shiner & 2 & 1 & 3 & 2 & 2 & 1 \\
\hline & & Cyprinella galactura & whitetail shiner & 2 & 1 & 3 & 2 & 3 & 2 \\
\hline & & Cyprinella spiloptera & spotfin shiner & 2 & 2 & 3 & 2 & 3 & 2 \\
\hline & & Exoglossum maxillingua & cutlips minnow & 2 & 1 & 3 & 2 & 2 & 2 \\
\hline & & Hybognathus regius & eastern silvery minnow & 2 & 2 & 3 & 2 & 3 & 1 \\
\hline & & Luxilus albeolus & white shiner & 2 & 1 & 3 & 2 & 2 & 2 \\
\hline & & Luxilus cerasinus & crescent shiner & 2 & 1 & 3 & 2 & 1 & 1 \\
\hline & & Luxilus chrysocephalus & striped shiner & 2 & 1 & 3 & 2 & 2 & 1 \\
\hline & & Luxilus coccogenis & warpaint shiner & 2 & 1 & 3 & 2 & 3 & 2 \\
\hline & & Luxilus cornutus & common shiner & 2 & 1 & 3 & 2 & 2 & 2 \\
\hline & & Lythrurus ardens & rosefin shiner & 2 & -9 & 3 & 2 & 2 & 2 \\
\hline & & Nocomis leptocephalus & bluehead chub & 2 & 1 & 3 & 2 & 2 & 1 \\
\hline & & Nocomis micropogon & river chub & 2 & 1 & 3 & 2 & 3 & 1 \\
\hline & & Nocomis platyrhynchus & bigmouth chub & 2 & 1 & 3 & 2 & 2 & 2 \\
\hline & & Nocomis raneyi & bull chub & 2 & 1 & 3 & 2 & 2 & 2 \\
\hline & & Notemigonus crysoleucas & golden shiner & 2 & 2 & 4 & 2 & 2 & 1 \\
\hline & & Notropis altipinnis & highfin shiner & 1 & 1 & 2 & 2 & 2 & 1 \\
\hline & & Notropis amblops & bigeve chub & 2 & -9 & 2 & 1 & 3 & 1 \\
\hline & & Notropis amoenus & comely shiner & 2 & 2 & 3 & 2 & 3 & 1 \\
\hline & & Notropis buccatus & silverjaw minnow & 1 & 1 & 3 & 1 & 3 & 2 \\
\hline & & Notropis chalybaeus & ironcolor shiner & 1 & 1 & 2 & 2 & 2 & 1 \\
\hline & & Notropis chiliticus & redlip shiner & 1 & 1 & 3 & 2 & 2 & 2 \\
\hline & & Notropis hudsonius & spottail shiner & 2 & 2 & 3 & 2 & 3 & 1 \\
\hline & & Notropis hypsinotus & highback chub & 1 & -9 & 2 & 1 & 2 & 1 \\
\hline & & Notropis leuciodus & Tennessee shiner & 1 & 1 & 3 & 2 & 3 & 1 \\
\hline & & Notropis procne & swallowtail shiner & 1 & 1 & 3 & 2 & 3 & 1 \\
\hline & & Notropis rubellus & rosyface shiner & 2 & 1 & 3 & 2 & 4 & 1 \\
\hline & & Notropis rubricroceus & saffron shiner & 1 & 1 & 3 & 2 & 2 & 2 \\
\hline & & Notropis semperasper & roughhead shiner & 2 & 2 & 3 & 2 & 3 & 1 \\
\hline & & Notropis stramineus & sand shiner & 1 & 1 & 3 & 2 & 3 & 1 \\
\hline & & Notropis telescopus & telescope shiner & 1 & 2 & 3 & 2 & 3 & 1 \\
\hline & & Notropis volucellus & mimic shiner & 1 & 1 & 3 & 2 & 3 & 1 \\
\hline & & Phoximis oreas & mountain redbelly dace & 1 & -9 & 3 & 2 & 2 & 2 \\
\hline & & Pimephales notatus & bluntnose minnow & 2 & 2 & 3 & 2 & 3 & 2 \\
\hline & & Rhinichthys atratulus & blacknose dace & 2 & 2 & 3 & 2 & 3 & 2 \\
\hline & & Rhinichthys cataractae & longnose dace & 2 & 2 & 3 & 1 & 4 & 2 \\
\hline & & Semotilus atromaculatus & creek chub & 2 & 2 & 4 & 2 & 3 & 2 \\
\hline & & Semotilus corporalis & fallfish & 3 & 2 & 4 & 2 & 3 & 1 \\
\hline & Catostomidae & Catostomus commersoni & white sucker & 3 & 2 & 4 & 1 & 3 & 1 \\
\hline & & Erimyzon oblongus & creek chubsucker & 2 & 2 & 4 & 1 & 2 & 2 \\
\hline & & Hypentelium nigricans & northern hog sucker & 3 & $-\overline{9}$ & 4 & 1 & 3 & 2 \\
\hline & & Moxostoma anisurum & silver redhorse & 3 & 2 & 4 & 1 & 2 & 1 \\
\hline & & Moxostoma ariommum & bigeye jumprock & 2 & -9 & 3 & 1 & 3 & 1 \\
\hline & & Moxostoma cervinum & black jumprock & 2 & -9 & 3 & 1 & 3 & 2 \\
\hline & & Moxostoma erythrurum & golden redhorse & 3 & 2 & 4 & 1 & 2 & 1 \\
\hline
\end{tabular}


APPENDIX. Continued.

\begin{tabular}{|c|c|c|c|c|c|c|c|c|c|}
\hline \multirow[b]{2}{*}{ Country } & \multirow[b]{2}{*}{ Family } & \multirow[b]{2}{*}{ Species } & \multirow[b]{2}{*}{ Common name } & \multicolumn{6}{|c|}{ Biological traits } \\
\hline & & & & $\mathrm{BL}$ & $\mathrm{FE}$ & MA & VP & $\mathrm{SH}$ & SW \\
\hline \multirow[t]{51}{*}{ USA (Virginia) } & & Moxostoma hamiltoni & rustyside sucker & 2 & 1 & 3 & 1 & 3 & 3 \\
\hline & & Moxostoma macrolepidotum & shorthead redhorse & 3 & 2 & 4 & 1 & 3 & 2 \\
\hline & & Moxostoma pappillosum & suckermouth redhorse & 3 & 2 & 4 & 1 & 3 & 1 \\
\hline & & Moxostoma rhothoecum & torrent sucker & 2 & 1 & 4 & 1 & 3 & 2 \\
\hline & & Moxostoma robustum & smallfin redhorse & 2 & -9 & 3 & 1 & 3 & 1 \\
\hline & Ictaluridae & Ameiurus natalis & yellow bullhead & 3 & 1 & 4 & 1 & 3 & 3 \\
\hline & & Ameiurus nebulosus & brown bullhead & 2 & 2 & 4 & 1 & 3 & 2 \\
\hline & & Ameiurus platycephalus & flat bullhead & 2 & 1 & 4 & 1 & 3 & 3 \\
\hline & & Ictalurus punctatus & channel catfish & 3 & 2 & 4 & 1 & 4 & 1 \\
\hline & & Noturus gyrinus & tadpole madtom & 1 & 1 & 3 & 1 & 2 & 3 \\
\hline & & Noturus insignis & margined madtom & 2 & 1 & 3 & 1 & 4 & 3 \\
\hline & Salmonidae & Oncorhynchus mykiss & rainbow trout & 3 & 2 & 4 & 2 & 3 & 1 \\
\hline & & Salmo trutta & brown trout & 3 & 1 & 4 & 2 & 2 & 1 \\
\hline & Aphredoderidae & Aphredoderus sayanus & pirate perch & 2 & 1 & 3 & 2 & 2 & 3 \\
\hline & Cyprinidontidae & Fundulus diaphanus & banded killifish & 2 & 1 & 3 & 2 & 3 & 3 \\
\hline & Poeciliidae & Gambusia affinis & mosquitofish & 1 & 1 & 1 & 2 & 2 & 3 \\
\hline & Cottidae & Cottus baileyi & black sculpin & 2 & 1 & 3 & 1 & 3 & 1 \\
\hline & & Cottus bairdi & mottled sculpin & 2 & 1 & 3 & 1 & 3 & 2 \\
\hline & & Cottus carolinae & banded sculpin & 2 & 1 & 3 & 1 & 3 & 1 \\
\hline & & Cottus girardi & Potomac sculpin & 2 & 1 & 3 & 1 & 2 & 1 \\
\hline & Centrarchidae & Acantharchus pomotis & mud sunfish & 2 & -9 & 4 & 2 & 1 & 3 \\
\hline & & Ambloplites rupestris & rock bass & 3 & 2 & 3 & 2 & 1 & 2 \\
\hline & & Centrarchus macropterus & flier & 2 & 2 & 4 & 2 & 1 & 2 \\
\hline & & Enneacanthus gloriosus & bluespotted sunfish & 1 & 1 & 3 & 2 & 1 & 2 \\
\hline & & Lepomis auritus & redbreast sunfish & 2 & 2 & 4 & 2 & 1 & 2 \\
\hline & & Lepomis cyanellus & green sunfish & 2 & 2 & 4 & 2 & 1 & 3 \\
\hline & & Lepomis gibbosus & pumpkinseed & 2 & 2 & 4 & 2 & 1 & 2 \\
\hline & & Lepomis gulosus & warmouth & 2 & 2 & 4 & 2 & 1 & 2 \\
\hline & & Lepomis macrochirus & bluegill & 2 & 2 & 3 & 2 & 1 & 2 \\
\hline & & Lepomis megalotis & longear sunfish & 2 & 2 & 3 & 2 & 1 & 3 \\
\hline & & Lepomis microlophus & redear sunfish & 2 & 2 & 3 & 2 & 1 & 2 \\
\hline & & Micropterus dolomieu & smallmouth bass & 3 & 2 & 4 & 2 & 1 & 1 \\
\hline & & Micropterus punctulatus & spotted bass & 3 & 2 & 4 & 2 & 1 & 1 \\
\hline & & Micropterus salmoides & largemouth bass & 3 & 2 & 4 & 2 & 1 & 2 \\
\hline & & Pomoxis nigromaculatus & black crappie & 3 & 2 & 4 & 2 & 1 & 1 \\
\hline & Percidae & Etheostoma blennioides & greenside darter & 2 & 1 & 3 & 1 & 2 & 3 \\
\hline & & Etheostoma caeruleum & rainbow darter & 1 & 1 & 3 & 1 & 2 & 3 \\
\hline & & Etheostoma flabellare & fantail darter & 1 & 1 & 3 & 1 & 3 & 3 \\
\hline & & Etheostoma fusiforme & swamp darter & 1 & -9 & 2 & 1 & 4 & 3 \\
\hline & & Etheostoma longimanum & longfin darter & 1 & 1 & 3 & 1 & 3 & 2 \\
\hline & & Etheostoma nigrum & johnny darter & 1 & 1 & 3 & 1 & 4 & 2 \\
\hline & & Etheostoma olmstedi & tessellated darter & 1 & 1 & 3 & 1 & 3 & 2 \\
\hline & & Etheostoma rufilineatum & redline darter & 1 & 1 & 3 & 1 & 2 & 3 \\
\hline & & Etheostoma simoterum & snubnose darter & 1 & 1 & 2 & 1 & 3 & 1 \\
\hline & & Etheostoma vitreum & glassy darter & 1 & 1 & 3 & 1 & 4 & 2 \\
\hline & & Perca flavescens & yellow perch & 2 & 2 & 4 & 2 & 1 & 2 \\
\hline & & Percina crassa & Piedmont darter & 1 & 1 & 3 & 1 & 3 & 3 \\
\hline & & Percina notogramma & stripeback darter & 1 & 1 & 3 & 1 & 3 & 2 \\
\hline & & Percina oxyrhyncha & sharpnose darter & 2 & -9 & -9 & 1 & 4 & 3 \\
\hline & & Percina peltata & shield darter & 1 & 1 & 3 & 1 & 4 & 2 \\
\hline & & Percina roanoka & Roanoke darter & 1 & 1 & 3 & 1 & 3 & 3 \\
\hline
\end{tabular}

Notes: Categories for each trait are ordinal. Biological traits are adult body length (BL), fecundity (FE), maximum age (MA), vertical position (VP), shape factor (SH), and swimming factor (SW). BL categories are: category $1,<8 \mathrm{~cm}$; category $2,8-32 \mathrm{~cm}$; category $3,>32 \mathrm{~cm}$. FE categories are potential number of eggs per year: category $1,<2000$ eggs; category 2, 2000-100000 eggs; category 3, > 100000 eggs. MA categories are: category 1, 1 yr; category 2, 2yr; category 3, 3-6 yr; category 4, >6 yr. VP categories are: category 1, benthic; category 2, nonbenthic (a species was classified as benthic if it possessed anatomy and behavior specialized for bottom living). SH categories were determined by the ratio of total body length to maximum body depth: category $1,<4$; category $2,4-5$; category $3,5-6$; category $4,>6$. SW factors were determined by the ratio of minimum depth of the caudal peduncle to the maximum caudal fin depth: category $1,<0.4 ;$ category $2,0.4-$ 0.5 ; category $3,>0.5$.

All missing values are indicated by “-9." Traits for French species were adapted from Persat et al. (1994) with morphometric information (SH, SW) measured in Terofal (1987). Traits for species from Virginia were derived from Lee et al. (1980), Page and Burr (1991), and Jenkins and Burkhead (1994), as described by Angermeier (1995), Poff and Allan (1995), and Angermeier and Winston (1999). 